\title{
Executive Functioning in Every Day Life in Ecuatorian Adolescents with Developmental Dyslexia
}

\author{
Manuel Soriano-Ferrer'1, Elisa Piedra-Martínez², Magali Arteaga ${ }^{3}$ \\ ${ }^{1}$ Departamento de Psicología Evolutiva y de la Educación, Facultad de Psicología, Universidad de Valencia, Valencia, Spain \\ ${ }^{2}$ Escuela de Educación Especial y Escuela de Psicologìa Educativa, Facultad de Filosofía Universidad del Azuay, Cuenca, Ecuador \\ ${ }^{3}$ Universidad del Azuay, Cuenca, Ecuador \\ Email: Manuel.Soriano@uv.es
}

How to cite this paper: Soriano-Ferrer, M., Piedra-Martínez, E., \& Arteaga, M. (2018). Executive Functioning in Every Day Life in Ecuatorian Adolescents with Developmental Dyslexia. Psychology, 9, 1050-1064. https://doi.org/10.4236/psych.2018.95066

Received: March 30, 2018

Accepted: May 18, 2018

Published: May 22, 2018

Copyright (c) 2018 by authors and Scientific Research Publishing Inc. This work is licensed under the Creative Commons Attribution International License (CC BY 4.0).

http://creativecommons.org/licenses/by/4.0/

\begin{abstract}
Introduction: Deficits in executive functions (EF) have been well documented using tests of neuropsychological performance in children and adolescents with developmental dyslexia. However, the behavioral assessment of EFs in dyslexia is very scarce. Objective: The objective of this study was to examine the EF of adolescents with dyslexia, in comparison with adolescents with typical development. We used the BRIEF-A Behavior Rating Inventory of Executive Function in Adults (BRIEF-A). Method: 19 adolescents with dyslexia and 20 adolescents with normal development, participated, matched in age, sex and IQ. Parents and adolescents themselves completed the BRIEF-A. Results: The results show that both parents and adolescents with dyslexia consider that they have more problems of EF in daily life, especially in metacognitive processes (initiation, WM, planning, supervision of tasks and planning-organization). In addition, parents reported a lower severity of EF deficiencies than adolescents themselves when detecting a lower percentage of scores above the clinical cut-off point. Conclusions: Adolescents and their parents do not always agree in $\mathrm{FE}$ assessments. Consequently, information from both informants is essential to understand and treat children with developmental dyslexia. The results coincide with the FE deficits found with neuropsychological tests.
\end{abstract}

\section{Keywords}

Developmental Dyslexia, Executive Functions, Daily Life

\section{Introduction}

Dyslexia is a specific learning disorder, manifested by unexpected difficulties in 
reading and spelling (APA, 2014; Lyon, Shaywitz, \& Shaywitz, 2003). It is considered to be of neurobiological origin. In fact, during the last two decades a large number of neuroimaging studies have shown, both volumetric differences in gray and white matter, and less activation in the three major brain circuits related to reading fluency (frontal, temporoparietal and occipitotemporal) as well as the location of different genes involved in the transmission of dyslexia (see review in Soriano-Ferrer \& Piedra-Martínez, 2017). In addition, different longitudinal studies conducted in orthographies with different degrees of transparency have shown that reading difficulties are relatively chronic and persistent in adolescence and adulthood (Bruck, 1992; Shaywitz, et al., 1999; Snowling, Muter, \& Carroll, 2007; Swanson \& Hsieh, 2009; Undheim, 2009; Wilson \& Lesaux, 2001).

Research carried out over the last forty years has shown that adolescents and adults with reading disabilities have a large number of deficits in cognitive processes related to reading. Recently, these deficiencies have been interpreted as a deficit in the executive functioning, which is understood as a construct that involves a series of functions (e.g. inhibition, attention, decision making, planning, working memory, self-monitoring and cognitive set shifting, Brosnan et al., 2002; Diamond, 2013; Elliott, 2003; Rosselli, Matute, \& Jurado, 2008; Stern \& Morris, 2013). Such functions allow individuals to self-regulate, and direct their behavior towards the achievement of goals (Lyon \& Krasnegor, 1996), especially on new behaviors and complex tasks (Wittlin, 2010). Different studies have shown a lack of executive functioning in children and adults with reading disabilities (Altemeier, Abbott, \& Berninger, 2008; Booth, Boyle, \& Kelly, 2010; Reiter, Tucha, \& Lange, 2005; Varvara, Varuzza, Sorrentino, Vicari, \& Menghini, 2014). In particular, the meta-analysis of 48 studies conducted by Booth et al. (2010) stresses that reading seems to depend more on inhibition, working memory, processing speed, change of attention and self-control.

The use of tasks of neuropsychological performance (e.g. stop task, verbal fluency, RAN/RAS, WCST, Tower of London, tasks go/no go) have allowed numerous studies to show that children and adolescents with reading disabilities have a worse performance in tasks of executive functioning. The affected tasks are the conservation and maintenance of information in the working memory (Beidas, Khateb, \& Breznitz, 2013; Brambati et al., 2006; Lervåg \& Hulme, 2009; Martinez Perez, Majerus, \& Poncelet, 2012; Smith-Spark \& Fisk, 2007; Menghini, Finzi, Carlesimo, \& Vicari, 2011; Roodenrys, Koloski, \& Grainger, 2001; Swanson, Zheng, \& Jerman, 2009; Van De Voorde, Roeyers, Verté, \& Wiersema, 2010; Willcutt, Pennington, Olson, Chhabildas, \& Hulslander, 2005; Willcutt et al., 2010). According to Brosnan et al. (2002) sequencing, planning and organization of information are also altered. Another criterion contributes to prove that verbal fluency or the ability to name words as quickly as possible according to an established criterion is also impaired (Brosnan et al., 2002; Stern \& Morris, 2013). Regarding the cognitive set shifting (Altemeier et al., 2008; Stern \& Morris, 2013) and the inhibition of irrelevant information and unwanted impulses 
(Brosnan et al, 2002, Altemeir, et al., 2008; Locascio, Mahone, Eason, \& Cutting 2010; Protopapas, Archonti, \& Skaloumbakas, 2007; Van der Schoot, Licht, Horsley, \& Sergeant, 2000; Wang, Tasi, \& Yang, 2012; Willcutt et al., 2005), they are also affected. Other studies do not find inhibitory difficulties in students with reading disabilities (Beidas et al., 2013; Silvestri, 2011).

However, research on executive functioning through neuropsychological performance tasks could be unrepresentative about how they work in everyday contexts since they are administered outside the natural environment of the child or adolescent. For this reason, other researchers have developed instruments for behavioral estimation of executive functioning. One of these instruments is the Behavior Rating Inventory of Executive Function (BRIEF, Gioia, Isquith, Guy, \& Kenworthy, 2000, BRIEF-A, Roth, Isquith, \& Gioia, 2005), which allows researchers to measure executive performance in day-to-day situations based on a estimation questionnaire while taking into consideration the different contexts (e.g. school, social, family and work). The few studies that have used questionnaires of behavioral estimation of executive functions in different ages conclude that students with reading disabilities have executive difficulties in everyday experiences. Gioia et al. (2000) in their study to clinically standardize cases in English-speaking children with reading disabilities determined significant difficulties in working memory and planning using only parent version. Likewise, in the study of Schöfl, Kloo, \& Kaufmann (2014) according to parent ratings of 17 German-speaking children with dyslexia showed higher levels of deficiencies in working memory and planning, and organization than healthy controls. Also, by using parent version, Spicer (2015) found more generalized and severe deficiencies in executive functions in English-speaking students with reading disabilities. In children and adolescents from 10 to 14 years old, Locascio et al. (2010) found a global index of executive dysfunction higher in students with reading disabilities, according to the assessments of their parents. Similarly, Smith-Spark, Henry, Messer, Edvardsdottir, \& Ziecik (2016) found more executive difficulties in the tasks of the metacognitive index (e.g. cognitive flexibility, working memory, planning, organization of tasks) than in the regulation of emotions and behavior in adults with reading disabilitiesby using only the self-report scale,

In summary, research developed using ratings of executive function is very scarce and limited for several reasons:

1) All studies, except for the work of Schöfl et al. (2014), have been developed with English-speaking children;

2) There has been research developed with children, except the work of Smith-Spark et al. (2016) that carried out a study with adults;

3) None of the studies have used different sources of estimation, nor have they made any comparison of the executive difficulties with two sources of information (self-report and observer report). In fact, studies have used only the estimates of parents, except the work of Smith-Spark et al. (2016) that exclusively 
uses the self-report version. Therefore, these limitations of the research have motivated the present study, which is the first study that analyzes executive functions from two sources of information (self-report and observers) in Spanish-speaking adolescents with dyslexia. Thus, the present study aims to: a) examine the profile of executive functioning in Spanish-speaking adolescents with reading disabilities based on their own assessments and those made by their parents as observers; b) compare the differential scores (calculated from the observer's assessments and the self-report itself) between adolescents with reading disabilities and those with typical development.

\section{Method}

\section{Participants}

The sample consisted of 39 Ecuadorian adolescents, with and without reading disabilities, selected from the last year of secondary school. The selection of the sample was made through the psycho-educational teams of three cities of Ecuador (Azogues, Cuenca and Guayaquil). School psychologists informed us about possible candidates with reading difficulties for the study. We contacted them to get their participation in the study. Participants were asked to collaborate in the study and signed the informed consent. Students were informed about the objective of the study and that they could withdraw from it the moment they felt like doing so. Students with difficulties were asked to contact with a friend of their class without reading difficulties who could collaborate in the study as a subject of the study in the control group. In this way it was controlled that the two groups belonged to the same social stratum.

The control group consisted of 20 subjects, 8 women and 12 men with an average age of 17 years and a standard deviation of .59. All of them with intelligence within normal and with adequate reading skills. In all cases, those participants who had a history of low academic performance and/or with educational needs, associated with some type of disability, were excluded from the study.

The group with reading disabilities was composed of 19 participants, 14 men and 5 women, with an average age of 16.85 and a standard deviation of .52. The students were from three cities (Azogues, Cuenca and Guayaquil).Thirteen of them already had a previous diagnosis of developmental dyslexia. The criteria in the selection of the group of participants with reading disabilities followed the diagnostic guidelines of the DSM-5 (APA, 2014). That is, participants had to show the following: 1) Non-verbal intelligence of 80 or more by means of the general capacity test (Factor "G") (Cattell \& Cattell, 1990); 2) significantly low reading performance in the individual application test, Battery of Evaluation of Reading Processes (PROLEC-SE, Ramos \& Cuetos, 2003). Specifically, those subjects who had a performance equal or lower than the 25th percentile (Pc 25) in the subtest of word reading and/or reading pseudo-words were selected; 3) exclusion criteria. From the analysis of the personal and academic history of the subjects, those participants with a history of brain injuries or neurological prob- 
lems, sensory deficiencies, school absenteeism, intellectual disability, as indicated by the DSM-5 (APA, 2014) were also excluded. Table 1 shows the descriptive data of the participants.

It was found that there were no differences between the groups in: gender, $\chi^{2}$ $(1)=.821, p>.05$; chronological age, $\mathrm{F}(1,38)=.737, p>.05, \eta^{2}=.002$; and non-verbal intelligence, $\mathrm{F}(1,38)=2592 ; p>.05 ; \eta^{2}=.008$. Clearly, both groups differ in their reading abilities. Thus, the participants in the group with reading disabilities obtained significantly lower scores than those in the control group, in both the word reading index, $\mathrm{F}(1,38)=55.502, p<.000, \eta^{2}=.60$, and in the pseudo-word reading index, $\mathrm{F}(1,38)=66.615, p<.000, \eta^{2}=.64$, with a high effect size.

\section{Evaluation Instruments}

Intelligence: The "g" Factor Test of Cattell \& Cattell was used. Scale 3 (1990) for adults, which consists of four sub-tests: series, classification, matrixes and conditions, which involve cognitive operations of identification, perceptual similarities, serialization, classification, matrixes and comparisons and involve different perceptual contents in order to prevent some perceptual differences from influencing the results when measuring intelligence. This test has a reliability of .86 .

Reading performance: as indicators of reading accuracy, the lexical processes subtest, word reading and pseudo-word reading of the PROLEC-SE secondary reading evaluation battery (Ramos \& Cuetos, 2003) were used. This test requires the correct identification of 40 words and 40 pseudo-words with different length, frequency, and graphemic complexity (CCV, CVV, CVC, CCVC, CVVC, VC). The successes and the time used in the reading were counted. In order to interpret more clearly the reading behavior of the participating groups, word reading and pseudo-word reading indexes were calculated, dividing the hits in each of the scales by the time spent reading them, and multiplying the results by 100 .

The BRIEF-A, Behavior Rating Inventory of ExecutiveFunction (Roth et al., 2005) was used. The BRIEF-A is a standardized questionnaire that assesses the executive or self-regulation functions in their daily environment. Two formats were used: a self-report and an informant report who is familiar with the daily functioning of the individual. The BRIEF-A consists of 75 items that generate 9

Table 1. Descriptive data for both groups.

\begin{tabular}{ccc}
\hline & Dyslexia group ( $=19)$ & Control group ( $=20)$ \\
\cline { 2 - 3 } & $\mathrm{M} \pm \mathrm{SD}$ & $\mathrm{M} \pm \mathrm{SD}$ \\
\hline Age & $16.85 \pm .52$ & $17 \pm .59$ \\
IQ (Factor "g") & $98.53 \pm 11.56$ & $104 \pm 9.62$ \\
Word Reading Index & $88.27 \pm 23.46$ & $142.09 \pm 21.64$ \\
Pseudoword Reading Index & $57.37 \pm 14.63$ & $89.96 \pm 9.97$
\end{tabular}


clinical subscales, which are grouped into two indexes: behavioral regulation index (BRI) composed of 4 subscales (Inhibit, Shift, Emotional Control, and Self-Monitor) and the metacognitive index (MI) composed of 5 subscales (Initiate, Working Memory, Plan/Organize, Task Monitor, and Organization of Materials). The Behavioral Regulation Index represents the ability to control and regulate emotional response, shift cognitive set and modulate behavior. The Inhibit scale (10 items) assesses the ability to suppress impulses and to stop one's own behavior at the appropriate time (e.g. "I tap my fingers or bounce my legs", "I am impulsive"). The Shift scale (6 items) assesses the ability to adjust behavior in a flexible manner according to a situation (e.g. "I have trouble changing from one activity or task to another", "I am bothered by having to deal with changes"). Emotional Control scale (10 items) measure the capacity to modulate emotional responses (e.g. "I have ungry outbursts", "My mood chances frequently"). Self-Monitor scale (6 items) assesses the ability to monitor one's own behaviors and the effects they have on people (e.g. "I talk at the wrong time ", "People say that I don't think before acting"). The Metacognitive Index represents the ability to solve for future-oriented problems in an organized, planned, systematic way, using working memory. The Initiate scale (8 items) reflects an individual's ability to begin a task or activity and to generate ideas, responses, or problem-solving strategies (e.g. "I lie around the house a lot", "I have trouble getting started on tasks"). The Working Memory scale (8 items) measures the capacity to hold information in memory in an active state for completing a task or production of a response (e.g. "I forget what I am doing in the middle of things", "I have a short attention span"). The Plan/Organize scale (10 items) measures an individual's ability to manage current and future task demands (e.g. "I have trouble prioritizing activities", "I have problems organizing activities"). The Task Monitor scale (6 items) reflects the capacity to track success or failure in solving a problem, and to identify and correct mistakes during behaviors (e.g. "I make careless errors when completing task", "I have problems completing my work"). The Organization of Materials scale (8 Items) provides information on the orderliness of work, home, and other personal spaces (e.g. "I am disorganized", "I leave my room or home a mess").Additionally, the questionnaire provides a global composite index (GEC) of all clinical subscales. The higher scores of the BRIEF-A indicate greater deterioration of executive functioning. The raw scores can be transformed (T-score) based on standardized population samples. The scores of $\geq 65$ were considered as clinically significant. The BRIEF-A is an instrument with adequate psychometric properties in terms of test-retest reliability (correlations ranging from .82 to .94) and internal consistency ( $\alpha$ coefficients ranging from .85 to .98). In addition, the support for the convergent and discriminant validity of the BRIEF-A has been reported by (Roth et al., 2005). In this study, the two versions, the self-report and the observer-report, were applied, and both have received positive evaluations in other investigations (for example, Pizzitola, 2002). 
All the evaluations were carried out in an isolated room of noises, designated only to investigation, at Universidad del Azuay in a session of an hour and a half. The parents filled in the questionnaire of the observer from BRIEF-A. To carry out the evaluation of the adolescents, the parents gave the written consent, in which they were informed of the confidentiality of the data, of the participation and the voluntary withdrawal of the study, and the objectives of the investigation according to the ethical parameters on research with human beings declared in Helsinki.

\section{Results}

After verifying that the data fulfilled the criterion of statistical normality, applying the Kolmogorov-Smirnov test, a multivariate analysis of variance (MANOVA) was performed with the group of origin as a grouping factor. After, an analysis of variance (ANOVA) for comparison between groups was carried out. For interpretation purposes, the Bonferroni correction $(.05 / 18=.002)$ was applied to determine the significance levels. In addition, the size of the effect was provided by the eta squared $\left(\eta^{2}\right)$, considering values between .01 and .10 as a small size effect, between .10 and .30 as the median effect and values greater than .30 as large effects.

Comparison between groups in the self-report questionnaires and the BRIEF-A Observer

The results of the MANOVA with the dependent measures indicate significant differences between the groups (Wilks' Lambda $(\Lambda)=.073, \mathrm{~F}(15,23)=8.240, \eta^{2}$ $=.92$, with a large effect size (see Table 2 ). In the self-report version, the scores of the adolescents with reading disabilities were significantly higher than those of the control group in the Global Executive Compound Index, F $(1,38)=$ $26.124 p=.000, \eta^{2}=.41$, as well as in the Metacognitive Index, $\mathrm{F}(1,38)=31.71$, $p=.000, \eta^{2}=.46$, with a large effect size in both cases. Specifically, of the 5 subscales that make up the metacognitive index, significant differences were found in four of them. Initiate, $\mathrm{F}(1,38)=13.17, p=.001, \eta^{2}=.26$, and Working Memory, $\mathrm{F}(1,38)=12.32, p=.001, \eta^{2}=.25$, with moderate effect size; Plan/Organize, F $(1,38)=23.22, p=.000, \eta^{2}=.38$, and Task Monitor, F $(1,38)$ $=33.18, p=.000, \eta^{2}=.47$, with a large effect size. Although the significant differences in the Index of Behavioral Regulation were not reached, significant difference were found in one of the 4 subscales: Inhibit, $\mathrm{F}(1,38)=4.539, p<.05$, $\eta^{2}=.11$, with a moderate effect size.

In relation to the results of the ANOVAs in the informant questionnaires, the parents indicated more difficulties in the executive functioning in the group of adolescents with developmental dyslexia (see Table 2). Thus, there are significant differences between the groups in the Executive Global Index, F $(1,38)=$ $21,063 p=.000, \eta^{2}=.36$, with a large effect size. In relation to the metacognitive index, the parents indicated significant differences, $\mathrm{F}(1,38)=24.98, p=.000, \eta^{2}$ $=.14$, with a moderate effect size. Additionally, parents expressed more difficulties 
Table 2. Descriptive data of the groups on all the scales and indices of the BRIEF-A for self-report and informant forms.

\begin{tabular}{ccccc}
\hline & \multicolumn{2}{c}{ BRIEF-A Self-Report } & \multicolumn{2}{c}{ BRIEF-A. Informant } \\
\cline { 2 - 5 } & $\begin{array}{c}\text { Dyslexia } \\
\text { group Dislexia } \\
(\mathbf{n}=\mathbf{1 9})\end{array}$ & $\begin{array}{c}\text { Control group } \\
(\mathbf{n}=\mathbf{2 0})\end{array}$ & $\begin{array}{c}\text { Dyslexia group } \\
(\mathbf{n}=19)\end{array}$ & $\begin{array}{c}\text { Control group } \\
(\mathbf{n}=\mathbf{2 0})\end{array}$ \\
\cline { 2 - 5 } & $\mathbf{M} \pm \mathrm{SD}$ & $\mathbf{M} \pm \mathrm{SD}$ & $\mathbf{M} \pm \mathrm{SD}$ & $\mathbf{M} \pm \mathrm{SD}$ \\
\hline Inhibit & $12.32 \pm 2.73$ & $10.85 \pm 1.38$ & $11.84 \pm 2.43$ & $10 \pm 1.26$ \\
Shift & $12.32 \pm 2.04$ & $8.10 \pm 2.33$ & $10.11 \pm 1.88$ & $8.35 \pm 1.87$ \\
Emotional Control & $15.95 \pm 3.99$ & $16.60 \pm 2.74$ & $17.21 \pm 3.34$ & $16.30 \pm 3.68$ \\
Self. Monitor & $8.42 \pm 2.17$ & $7.65 \pm 1.50$ & $9.79 \pm 2.57$ & $8.70 \pm 2.15$ \\
Initiate & $13.63 \pm 1.64$ & $11.40 \pm 2.13$ & $13.84 \pm 3.02$ & $11.90 \pm 2.88$ \\
Working Memory & $13.42 \pm 2.93$ & $10.50 \pm 2.23$ & $13.05 \pm 2.97$ & $9.75 \pm 2.09$ \\
Plan/Organize & $21.47 \pm 3.22$ & $16.95 \pm 2.62$ & $19.79 \pm 4.37$ & $13.50 \pm 2.89$ \\
Task Monitor & $12.63 \pm 2.03$ & $9.05 \pm 1.85$ & $11.26 \pm 2.23$ & $8.55 \pm 1.15$ \\
Org. of Materials & $14.21 \pm 3.01$ & $13.20 \pm 3.14$ & $15.11 \pm 3.79$ & $12.60 \pm 3.20$ \\
Behavioral Reg. Index & $46.15 \pm 6.50$ & $43.20 \pm 4.09$ & $48.94 \pm 7.32$ & $43.35 \pm 6.89$ \\
Metacognition Index & $75.36 \pm 6.90$ & $61.10 \pm 8.75$ & $73.05 \pm 12.30$ & $56.30 \pm 8.34$ \\
Global (GEC) & $121.05 \pm 9.52$ & $104 \pm 11.19$ & $121.53 \pm 16.95$ & $99.45 \pm 12.91$ \\
\hline
\end{tabular}

in the group of adolescents with dyslexia in the five subscales that make up the metacognitive index. Initiate, $\mathrm{F}(1,38)=4.210, p<.05, \eta^{2}=.10$, Working Memory, $\mathrm{F}(1,38)=24,693, p<.000, \eta^{2}=.30$, Plan/Organize, $\mathrm{F}(1,38)=28,399, p$ $=.000, \eta^{2}=.43$, Task Monitor, $\mathrm{F}(1,38)=23,150, p=.000, \eta^{2}=.38$, Organization of Materials, $\mathrm{F}(1,38)=4.977, p<.05, \eta^{2}=.11$, with moderate or high effect sizes.

In relation to the Index of Behavioral Regulation, parents also expressed more executive difficulties in adolescents with dyslexia, $\mathrm{F}(1,38)=6.042, p<.05, \eta^{2}$ $=.14$, with a moderate effect size. However, parents only detect significant differences in two of the 4 subscales: Inhibit, $\mathrm{F}(1,38)=8.96, p=.005, \eta^{2}=.18$, and Shift, $\mathrm{F}(1,38)=8.52, p<.05, \eta^{2}=.13$, with moderate effect size.

Percentages of adolescents that exceed the clinical cut-off

The percentages of adolescents who obtained scores in the different BRIEF-A subscales and indexes that exceeded $\mathrm{T} \geq 65$, which were considered clinically significant, were calculated. As can be seen in Figure 1 and Figure 2, the number of adolescents who obtained scores $\mathrm{T} \geq 65$ and that can be considered clinically significant is greater in the group with dyslexia, both in the self-report questionnaire and in the observer's questionnaire. BRIEF-A, which in this case were the parents. In general, it is the adolescents with dyslexia themselves who showed the greatest number of difficulties in executive functions that their parents value.

Specifically, in the self-report scale the number of clinical cases was higher in 
the subscales that make up the Metacognitive Index (see Figure 1): $1(5.27 \%)$ in Initiative, 3 (15.8\%) in working memory; 15 (79\%) in Plan/ Organize, 12 (63.16) in Task Monitor and 1 (5.27\%) in Organization of Materials. In the case of the subscales of the Index of Behavioral Regulation, the subjects above the clinical cut-off point are much lower: 1 (5.27\%) for the subscales (Inhibit, Emotional Control and Self-Monitor) and $2(10.53 \%)$ for the subscale (Shift).

In the scale of the informant, more clinical cases were also found in the dyslexia group, although notoriously less than those reported by adolescents with dyslexia, especially in the subscales of the Metacognitive index (see Figure 2): 5 (26.32\%) in Plan/Organize, 3 (15.8\%) in Task Monitor, and 2 (10.53\%) in Initiate, Working Memory and Organization of Materials. In relation to the subscales of the Index of Behavioral Regulation, the cases that exceeded the clinical cut-off were much lower: 2 (10.53\%) in Shift and 1 (5.27\%) in Self-Monitor.

Differential scores between self-perceptions and the perceptions of the observer

Figure 3 shows the average scores of the differential scores between the adolescents with dyslexia and the normo-reader adolescents, calculated by subtracting the $\mathrm{T}$ scores of the observer (the parents) from the $\mathrm{T}$ scores of the self-reports. Positive differential scores indicated that parents (observers) expressed more executive difficulties than adolescents self-perceive, while negative scores indicated that adolescents were the ones who perceived themselves with the most problems in executive functioning in regard to their parents' evaluations.

In general, adolescents perceive themselves with more difficulties in almost all domains of executive functioning regarding the evaluations made by their parents. The exception was Self-Monitor, where parents made the most negative

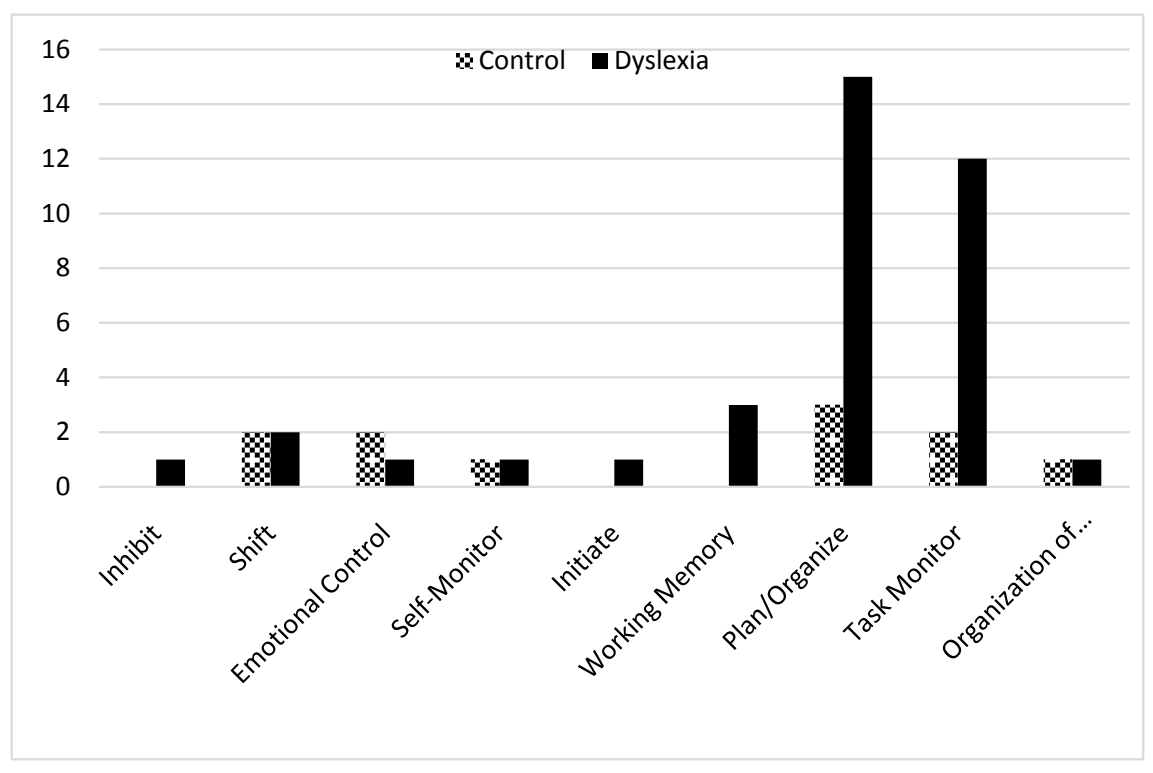

Figure 1. Number of cases above the clinical cut-off $(T \geq 65)$ for the Self-Report form (BRIEF-A). 


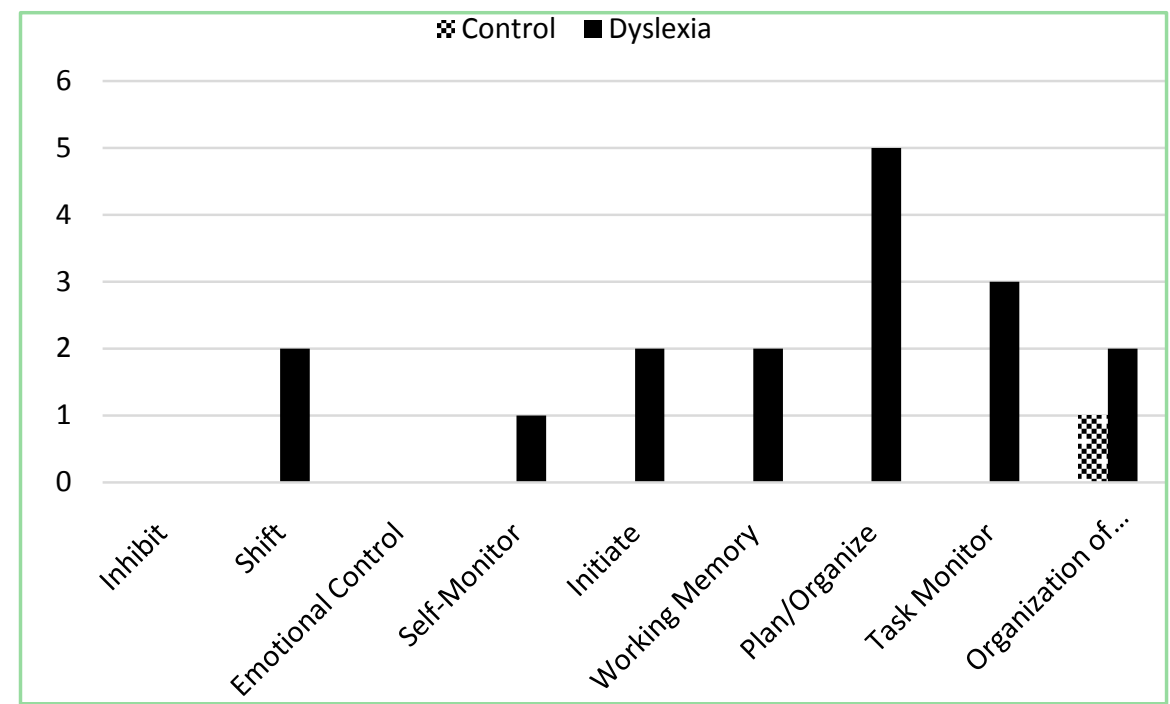

Figure 2. Number of cases above the clinical cut-off $(T \geq 65)$ for Informant form (BRIEF-A).

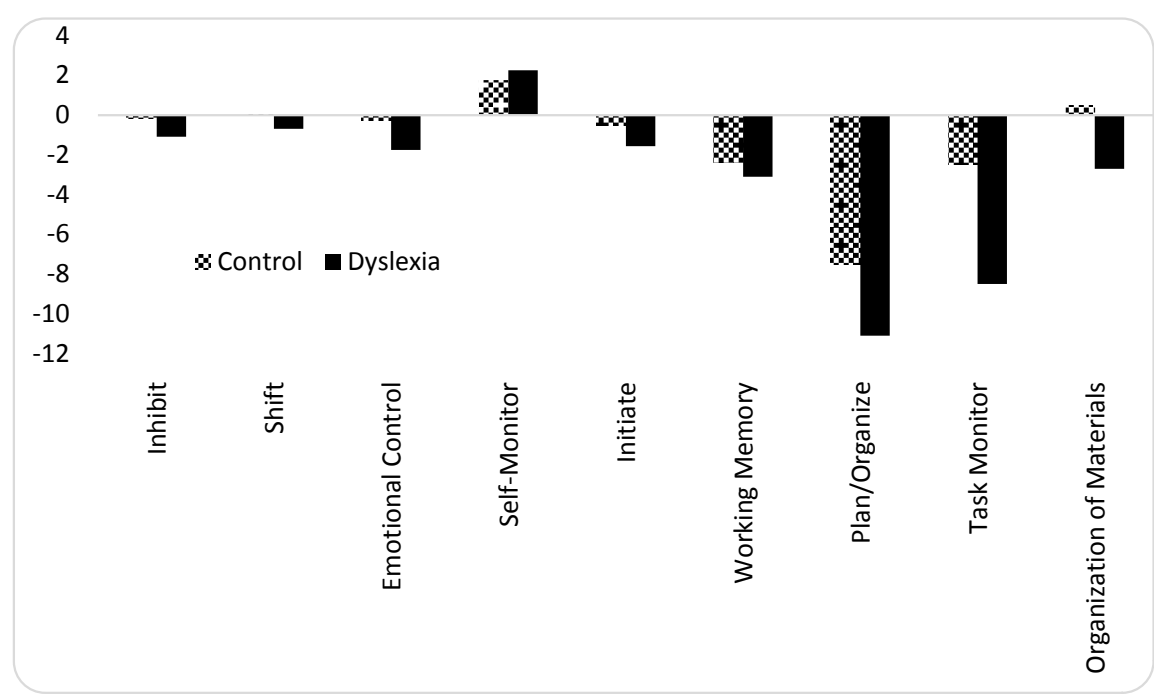

Figure 3. Mean of the differential scores in the BRIEF-A subscales.

assessments of their abilities. However, in the other domains of executive functioning, adolescents with dyslexia were the ones who made the most negative evaluations of themselves, especially in the skills of Plan/Organize and Task Monitor, in comparison to the normo-reader adolescents. In spite of the differences, they do not they reach statistical significance.

\section{Discussion}

The aim of this research was to examine the executive functions in adolescents with dyslexia and to compare them to adolescents with typical development using a scale of evaluation of executive functioning in daily life.

Adolescents with dyslexia perceive themselves and are perceived by their family with more problems in the executive functioning in their daily activities, 
compared to their normo-reader peers, especially in the subscales of the metacognitive index (Initiate, Working Memory, Plan/Organize, Organization of Materials). Although to a lesser extent, they also experience difficulties in some of the subscales of the behavioral regulation index (Inhibit and Shift). Thus, adolescents perceive themselves and are perceived by their parents with serious difficulties to face and resolve everyday situations of life. That is, they seem to maintain generalized deficits in executive functions of daily life similar to the few studies conducted with behavioral scales (e.g. Locascio et al., 2010; Schöfl et al., 2014; Smith-Spark et al., 2016; Spicer, 2015). Zelazo \& Müller (2002) differentiated between cold and hot executive functions; cold EFs tend to be used in abstract, decontextualized tasks, while hot EF are involved when tasks have a motivational meaning for the individual and in its control. The two types of Executive Functions are used to address real-world problems (e.g. Zelazo, 2015). Giancola, Godlaski, \& Roth (2012) associated the metacognition index with cold EF and the regulation index of the behavior with warm EF. From this perspective, our results suggest more difficulties in cold EF in adolescents with dyslexia, while warm EF are less altered.

Our data, although not statistically significant, point out that adolescents with dyslexia make more negative descriptions of themselves than their parents do of their executive functioning. This aspect is also supported by the large number of adolescents, whose self-reports exceed the cut-off points of clinical significance, which reach between $60 \%-80 \%$ of the cases in Plan/Organize and Task Monitor. This aspect of our data is new for two reasons. Thus, these data suggest that adolescents with dyslexia under estimate their own abilities; that is, they do not show the positive illusory bias, which has been so consistently described in children and adolescents with Attention Deficit Hyperactivity Disorder, who tend to be overrated in their abilities (e.g. Stewart, Tan, Delgaty, Gonzales, \& Bunner, 2017).

Finally, it is important to refer to the limitations of our study. First, ratings scales have limitations, since they may be subject to informants' biases, since their estimates of executive functions could be influenced by prejudices and previous experiences. Future studies should explore the source of the discrepancies by using an independent evaluator who would observe on a day-to-day basis. Another limitation is the BRIEF-A scale itself, which assesses many executive functions globally, but does not perform a thorough analysis of any of them. However, the use of rating scales is recommended as part of a thorough psychological exploration of reading difficulties, since they can be useful in the planning and evaluation of treatment (Roth et al., 2005). In fact, our results highlight, both with the adolescents "own evaluations and with their parents" ratings, that a relatively large percentage of Spanish-speaking adolescents with reading difficulties manifest a large number of executive dysfunctions, especially in metacognitive processes (initiation, WM, planning, supervision of tasks and planning-organization). They are also important for intervention, since difficulties in 
executive functioning could be addressed. In fact, some works have already begun to demonstrate the effectiveness of cognitive training in $\mathrm{FE}$, especially working memory (e.g. Horowitz-Kraus \& Breznitz, 2009; Luo, Wang, Wu, Zhu, \& Zhang, 2013; Shiran \& Breznitz, 2011; Tilanus, Segers, \& Verhoeven, 2016; Yang, Peng, Zhang, Zheng, \& Mo, 2017).

\section{References}

Altemeier, L. E., Abbott, R. D., \& Berninger, V. W. (2008). Executive Functions for Reading and Writing in Typical Literacy Development and Dyslexia. Journal of Clinical and Experimental Neuropsychology, 30, 588-606. https://doi.org/10.1080/13803390701562818

APA (American Psychiatric Association) (2014). Manual Diagnóstico y Estadístico de losTrastornosMentales. DSM-5. [Diagnostic and Statistical Manual of Mental Disorders, Five Edition]. Madrid: E. Médica Panamericana

Beidas, H., Khateb, A., \& Breznitz, Z. (2013). The Cognitive Profile of Adult Dyslexics and Its Relation to Their Reading Abilities. Reading and Writing, 26, 1487-1515. https://doi.org/10.1007/s11145-013-9428-5

Booth, J. N., Boyle, J. M., \& Kelly, S. W. (2010). Do Tasks Make a Difference? Accounting for Heterogeneity of Performance of Children with Reading Difficulties on Tasks of Executive Function: Findings from a Meta-Analysis. British Journal of Developmental Psychology, 28, 133-176. https://doi.org/10.1348/026151009X485432

Brambati, S. M., Termine, C., Ruffino, M., Danna, M., Lanzi, G., Stella, G. et al. (2006). Neuropsychological Deficits and Neural Dysfunction in Familial Dyslexia. Brain Research, 1113, 174-185. https://doi.org/10.1016/j.brainres.2006.06.099

Brosnan, M., Demetre, J., Hamill, S., Robson, K., Shepherd, H., \& Cody, G. (2002). Executive Functioning in Adults and Children with Developmental Dyslexia. Neuropsychologia, 40, 2144-2155. https://doi.org/10.1016/S0028-3932(02)00046-5

Bruck, M. (1992). Persistence of Dyslexics' Phonological Awareness Deficits. Developmental psychology, 28, 874-886. https://doi.org/10.1037/0012-1649.28.5.874

Cattell, R. B., \& Cattell, A. K. S. (1990). Tests de factor" g", escalas 2 y 3. Tea Ediciones.

Diamond, A. (2013). Executive Functions. Annual Review of Psychology, 64, 135-168. https://doi.org/10.1146/annurev-psych-113011-143750

Elliott, R. (2003). Executive Functions and Their Disorders. British Medical Bulletin, 65, 49-59. https://doi.org/10.1093/bmb/65.1.49

Giancola, P. R., Godlaski, A. J., \& Roth, R. M. (2012). Identifying Component-Processes of Executive Functioning that Serve as Risk Factors for the Alcohol-Aggression Relation. Psychology of Addictive Behaviors, 26, 201-211. https://doi.org/10.1037/a0025207

Gioia, G. A., Isquith, P. K., Guy, S. C., \& Kenworthy, L. (2000). Behavior Rating Inventory of Executive Function: BRIEF. Odessa, FL: Psychological Assessment Resources.

Horowitz-Kraus, T., \& Breznitz, Z. (2009). Can the Error Detection Mechanism Benefit from Training the Working Memory? A Comparison between Dyslexics and Controls-An ERP Study. PloS One, 4, e7141. https://doi.org/10.1371/journal.pone.0007141

Lervåg, A., \& Hulme, C. (2009). Rapid Automatized Naming (RAN) Taps a Mechanism that Places Constraints on the Development of Early Reading Fluency. Psychological 
Science, 20, 1040-1048.

https://doi.org/10.1111/j.1467-9280.2009.02405.x

Locascio, G., Mahone, E. M., Eason, S. H., \& Cutting, L. E. (2010). Executive Dysfunction among Children with Reading Comprehension Deficits. Journal of learning disabilities, 43, 441-454. https://doi.org/10.1177/0022219409355476

Luo, Y., Wang, J., Wu, H., Zhu, D., \& Zhang, Y. (2013). Working-Memory Training Improves Developmental Dyslexia in Chinese Children. Neural Regeneration Research, 8 , 452-460.

Lyon, G. R., Shaywitz, S. E., \& Shaywitz, B. A. (2003). A Definition of Dyslexia. Annals of Dyslexia, 53, 1-14. https://doi.org/10.1007/s11881-003-0001-9

Lyon, G., \& Krasnegor, N. A. (Eds.) (1996). Attention, Memory, and Executive Function. Baltimore, MD: Brookes.

Martinez Perez, T., Majerus, S., \& Poncelet, M. (2012). The Contribution of Short-Term Memory for Serial Order to Early Reading Acquisition: Evidence from a Longitudinal Study. Journal of Experimental Child Psychology, 111, 708-723. https://doi.org/10.1016/j.jecp.2011.11.007

Menghini, D., Finzi, A., Carlesimo, G. A., \& Vicari, S. (2011). Working Memory Impairment in Children with Developmental Dyslexia: Is It Just a Phonological Deficity? Developmental Neuropsychology, 36, 199-213.

Pizzitola, K. M. (2002). Test Review: Behavior Rating Inventory of Executive Function. Journal of Psychoeducational Assessment, 20, 400-405.

Protopapas, A., Archonti, A., \& Skaloumbakas, C. (2007). Reading Ability Is Negatively Related to Stroop Interference. Cognitive Psychology, 54, 251-282. https://doi.org/10.1016/j.cogpsych.2006.07.003

Ramos, J. L., \& Cuetos, F. (2003). Evaluación de los Procesos Lectores PROLEC-SE. Madrid: TEA.

Reiter, A., Tucha, O., \& Lange, K. W. (2005). Executive Functions in Children with Dyslexia. Dyslexia, 11, 116-131. https://doi.org/10.1002/dys.289

Roodenrys, S., Koloski, N., \& Grainger, J. (2001). Working Memory Function in Attention Deficit Hyperactivity Disordered and Reading Disabled Children. British Journal of Developmental Psychology, 19, 325-337. https://doi.org/10.1348/026151001166128

Rosselli, M., Matute, E., \& Jurado, M. B. (2008). Las funciones ejecutivas a través de la vida. Revista Neuropsicología, Neuropsiquiatría y Neurociencias, 8, 23-46.

Roth, R. M., Isquith, P. K., \& Gioia, G. A. (2005) BRIEF-A Behavior Rating Inventory of Executive Function. Australia: PAR.

Schöfl, M., Kloo, D., \& Kaufmann, L. (2014). Planungsleistungen bei Grundschülern mit ADHS und LRS. Lernen und Lernstörungen, 4, 9-29.

Shaywitz, S. E., Fletcher, J. M., Holahan, J. M., Shneider, A. E., Marchione, K. E., Stuebing, K. K. et al. (1999). Persistence of Dyslexia: The Connecticut Longitudinal Study at Adolescence. Pediatrics, 104, 1351-1359. https://doi.org/10.1542/peds.104.6.1351

Shiran, A., \& Breznitz, Z. (2011). The Effect of Cognitive Training on Recall Range and Speed of Information Processing in the Working Memory of Dyslexic and Skilled Readers. Journal of Neurolinguistics, 24, 524-537. https://doi.org/10.1016/j.jneuroling.2010.12.001

Silvestri, R. (2011). Attention and Executive Functions Performance in Postsecondary Students with $A D / H D$ and Dyslexia. Doctoral Dissertation, Kingston, Ontario: Queen's University. 
Smith-Spark, J. H., \& Fisk, J. E. (2007). Working Memory Functioning in Developmental Dyslexia. Memory, 15, 34-56. https://doi.org/10.1080/09658210601043384

Smith-Spark, J. H., Henry, L. A., Messer, D. J., Edvardsdottir, E., \& Zięcik, A. P. (2016). Executive Functions in Adults with Developmental Dyslexia. Research in Developmental Disabilities, 53-54, 323-341. https://doi.org/10.1016/j.ridd.2016.03.001

Snowling, M. J., Muter, V., \& Carroll, J. (2007). Children at Family Risk of Dyslexia: A Follow-Up in Early Adolescence. Journal of Child Psychology and Psychiatry, 48, 609-618. https://doi.org/10.1111/j.1469-7610.2006.01725.x

Soriano-Ferrer, M., \& Piedra-Martínez, E. (2017). Una revisión de las bases neurobiológicas de la dislexia en población adulta. Neurología, 32, 50-57. https://doi.org/10.1016/j.nrl.2014.08.003

Spicer, M. P. (2015). Executive Function Skill Deficits in Children with Dislexia. Doctoral Dissertation, Murfreesboro, TN: Middle Tennessee State University.

Stern, S. K., \& Morris, M. K. (2013). Discrimination of ADHD and Reading Disability in Adults Using the D-KEFS. Archives of Clinical Neuropsychology, 28, 125-134. https://doi.org/10.1093/arclin/acs111

Stewart, K. A., Tan, A., Delgaty, L., Gonzales, M. M., \& Bunner, M. (2017). Self-Awareness of Executive Functioning Deficits in Adolescents with ADHD. Journal of Attention Disorders, 21, 316-322. https://doi.org/10.1177/1087054714530782

Swanson, H. L., Zheng, X., \& Jerman, O. (2009). Working Memory, Short-Term Memory, and Reading Disabilities. Journal of Learning Disabilities, 42, 260-287. https://doi.org/10.1177/0022219409331958

Swanson, L., \& Hsieh, C. J. (2009). Reading Disabilities in Adults: A Selective Meta-Analysis of the Literature. Review of Educational Research, 79, 1362-1390. https://doi.org/10.3102/0034654309350931

Tilanus, E. A., Segers, E., \& Verhoeven, L. (2016). Responsiveness to Intervention in Children with Dyslexia. Dyslexia, 22, 214-232. https://doi.org/10.1002/dys.1533

Undheim, A. M. (2009). A Thirteen-Year Follow-Up Study of Young Norwegian Adults with Dyslexia in Childhood: Reading Development and Educational Levels. Dislexia, 15, 291-303. https://doi.org/10.1002/dys.384

Van De Voorde, S., Roeyers, H., Verté, S., \& Wiersema, J. R. (2010). Working Memory, Response Inhibition, and Within-Subject Variability in Children with Attention-Deficit/Hyperactivity Disorder or Reading Disorder. Journal of Clinical and Experimental Neuropsychology, 32, 366-379. https://doi.org/10.1080/13803390903066865

van der Schoot, M., Licht, R., Horsley, T. M., \& Sergeant, J. A. (2000). Inhibitory Deficits in Reading Disability Depend on Subtype: Guessers but Not Spellers. Child Neuropsychology, 6, 297-312. https://doi.org/10.1076/chin.6.4.297.3139

Varvara, P., Varuzza, C., Padovano Sorrentino, A. C., Vicari, S., \& Menghini, D. (2014). Executive Functions in Developmental Dyslexia. Frontiers in Human Neuroscience, 8 , 120. https://doi.org/10.3389/fnhum.2014.00120

Wang, L. C., Tasi, H. J., \& Yang, H. M. (2012). Cognitive Inhibition in Students with and without Dyslexia and Dyscalculia. Research in Developmental Disabilities, 33, 1453-1461. https://doi.org/10.1016/j.ridd.2012.03.019

Willcutt, E. G., Betjemann, R. S., McGrath, L. M., Chhabildas, N. A., Olson, R. K., DeFries, J. C., \& Pennington, B. F. (2010). Etiology and Neuropsychology of Comorbidity between RD and ADHD: The Case for Multiple-Deficit Models. Cortex, 46, 1345-1361. https://doi.org/10.1016/j.cortex.2010.06.009

Willcutt, E. G., Pennington, B. F., Olson, R. K., Chhabildas, N., \& Hulslander, J. (2005). 
Neuropsychological Analyses of Comorbidity between Reading Disability and Attention Deficit Hyperactivity Disorder: In Search of the Common Deficit. Developmental Neuropsychology, 27, 35-78. https://doi.org/10.1207/s15326942dn2701_3

Wilson, A. M., \& Lesaux, N. K. (2001). Persistence of Phonological Processing Deficits in College Students with Dyslexia Who Have Age-Appropriate Reading Skills. Journal of Learning Disabilities, 34, 394-400. https://doi.org/10.1177/002221940103400501

Wittlin, N. E. (2010). Diagnostic Utility of Executive Function Assessment for Adults with Learning Disorders in Reading and Mathematics. Doctoral Dissertation, Teaneck, Madison, NJ: Fairleigh Dickinson University.

Yang, J., Peng, J., Zhang, D., Zheng, L., \& Mo, L. (2017). Specific Effects of Working Memory Training on the Reading Skills of Chinese Children with Developmental Dyslexia. PLoS ONE, 12, e0186114. https://doi.org/10.1371/journal.pone.0186114

Zelazo, P. D. (2015). Executive Function: Reflection, Iterative Reprocessing, Complexity and the Development of the Brain. Developmental Review, 38, 55-68. https://doi.org/10.1016/j.dr.2015.07.001

Zelazo, P. D., \& Müller, U. (2002). Executive Function in Typical and Atypical Development. In U. Goswami (Ed.), Handbook of Childhood Cognitive Development (pp. 445-469). Oxford: Blackwell. https://doi.org/10.1002/9780470996652.ch20 